\title{
DEL LIBERALISMO A LA CALIDAD EDUCATIVA
}

\section{FROM LIBERALISM TO QUALITY EDUCATION}

\section{Luis Alberto García Domínguez ${ }^{1}$}

\begin{abstract}
Resumen
La ambigüedad del concepto de calidad educativa ha puesto de manifesto la necesidad de estudiar el origen del mismo en un contexto mucho más amplio que el educativo. El presente trabajo establece ese marco referencial histórico que antecede y explica la utilización de este concepto, para enfatizar su naturaleza económica y su consecuente inserción en la política educativa.
\end{abstract}

Palabras clave: Liberalismo; Neoliberalismo; Educación; Calidad; Evaluación.

\begin{abstract}
The ambiguity regarding the quality education concept has revealed the need to study its origin in a much broader context than solely education. This paper establishes the preceding historical background and explains the use of this concept, emphasizing its economic nature and its subsequent insertion in the education policy.
\end{abstract}

Keywords: Liberalism; Neoliberalism; Education; Quality; Evaluation.

doi: http://dx.doi.org/10.15359/eys.19-46.3

Fecha de recepción: 5 de octubre del 2014. Fecha de aceptación: 29 de noviembre del 2014. Fecha de publicación: 22 de diciembre del 2014.

${ }^{1}$ Doctor, Instituto Tecnológico de Mérida, México. Correo electrónico: luisalbertogarciadominguez@gmail.com 


\section{Del liberalismo al neoliberalismo}

\section{Secuencia histórica}

La ubicación de los fundamentos teóricos y filosóficos que han dado cauce al desarrollo de la corriente política y económica que ha predominado en los últimos años del siglo XX y principios del XXI es el primer paso para estar en posibilidades de comprender su impacto, así como los aspectos medulares que la caracterizan.

Antes de discutir los principios neoliberales, es necesario hacer un breve recorrido por los antecedentes teóricos de esta corriente, para situarnos históricamente en el final de la lucha de la burguesía contra la iglesia y los restos del feudalismo imperante en la edad media.

Por lo tanto, nos encontramos con el liberalismo, movimiento cuyo surgimiento, según Serra Rojas (1988), se da como resultado de un acuerdo implícito entre los individuos en su oposición al poder absoluto del rey en una etapa de crisis histórica y en cuyos inicios fue condenado por la Iglesia debido a su carácter anticlerical, acusado de postulados de individualismo nefasto y amoral. Es posible encontrar antecedentes de un liberalismo clásico en autores como: Locke, Spinoza y Althusius. Además de los anteriores, se destacaron sobre el tema, otros como: Montesquieu, Tocqueville, Voltaire y Diderot, John Stuart Mill, Adam Smith, Ricardo y Bentham. Sin embargo, el epíteto liberal según Serra Rojas (1988) procede de un partido político español de inicios del siglo XIX, el cual luchaba por lograr un gobierno constitucional en su país. Antes de lo anterior con aquel término se hacía referencia a virtudes tales como el buen razonamiento o la generosidad.

Poco a poco las ideas liberales encontraron soporte en la concepción de un nuevo ser humano, en oposición al intervencionismo del Estado, al cual confinaban a convertirse en un simple espectador de la realidad social.

En su primera concepción el liberalismo implicaba según John Gray (1994), la primacía moral del ser humano frente a los grupos sociales, la cual le confiere un valor moral equitativo, para dejar en un segundo plano a la cultura y demás asociaciones históricas. Esa afirmación es interesante, dado que recoge la esencia de un movimiento liberador del ser humano, ante el sometimiento del señor feudal y en general de cualquier otro grupo. 
John Gray $^{2}$ (1994) afirma que los postulados del liberalismo constituyen los rasgos más característicos de la vida moderna, dado que su concepción solo pudo originarse en una época posterior a la edad media.

En los inicios del liberalismo, la victoria del parlamento sobre el rey permitió la constitución de los Estados representativos, en los cuales la figura del rey fue sustituida por la de un representante de la ciudadanía, el cual es electo por ellos mismos. De esta guisa se ampliaron los derechos de los nuevos gobernados al conferírseles la potestad de elegir a quienes los gobiernan. Estos fueron los inicios de la democracia moderna y su relación con el incipiente liberalismo ${ }^{3}$

Ahora bien, el sistema liberal fue el modelo seguido por los países que históricamente han constituido la vanguardia en el mundo moderno, y es cierto que el liberalismo al ser el modelo dominante en el siglo XIX contribuyó a la instauración de Estados democráticos, sin embargo sus defectos provocaron poco a poco su pérdida de influencia en el mundo. Este liberalismo según Serra Rojas (1988) condujo a un liberalismo político que puso al Estado al servicio de unos cuantos intereses exclusivos ${ }^{4}$.

Independientemente de lo anterior, el liberalismo tuvo que sufrir una transición, el ejercicio de las libertades proclamadas fue nada más un instrumento para la burguesía que se aprovechó de un sistema que le favoreció durante varias décadas.

Bien es cierto que el mundo fue encontrando en el liberalismo la corriente filosófica, política y económica predominante, ante la cual se abrió paso el nuevo siglo XX. Sin embargo las crisis revolucionarias y sobre todo las grandes desigualdades provocadas por las formas de gobierno sustentadas en una visión liberal, fueron la base de críticas que pedían una mayor participación y regulación de parte del Estado. Dichas críticas encontraban sus postulados en los principios keynesianos que pretendían una actuación del Estado más activa y decisiva en la economía,

2 “... Sus postulados constituyen los rasgos distintivos de la vida moderna: el individuo moderno con su inquietud por la libertad y la privacidad, por el crecimiento de la riqueza y un flujo económico de invención e innovación, y por la maquinaria del gobierno, indispensable para la vida civil y a la vez amenaza permanente para la misma (Gray, 1994$, p. 126$)^{\prime \prime}$.

3 “...Esquemáticamente, la relación entre el liberalismo y la democracia puede ser representada de acuerdo con estas tres combinaciones: a) liberalismo y democracia son compatibles y por tanto pueden convivir, en el sentido de que puede existir un Estado liberal y democrático sin que por lo demás se pueda excluir un Estado liberal no democrático y un Estado democrático no liberal...; b) liberalismo y democracia son antitéticos, en el sentido de que la democracia en sus consecuencias extremas termina por destruir al Estado liberal...; c) liberalismo y democracia están ligados necesariamente en el sentido de que sólo la democracia es capaz de realizar en plenitud los ideales liberales y sólo el Estado liberal puede ser la condición para la práctica de la democracia" (Bobbio, 2006, pp. 5859).

4 “... Las libertades resultaban ser libertades de contenido únicamente para la burguesía” (Serra, 1988, p. 238). 
sobre todo en áreas estratégicas que permitieran frenar la gran recesión y una mejor asignación de los recursos ${ }^{5}$.

Por otro lado, ante las anteriores y otras críticas hubo autores que empezaron a buscar una respuesta dentro del propio mercado, de tal manera que se concibe a este mismo como el regulador para la asignación de recursos, lo cual se basa en los principios liberales para reducir con esto aún más la participación del Estado por creerlo innecesario al menos en el plano económico.

Friederich A. Hayek, inglés de origen austríaco, fue uno de los precursores de este movimiento. En su texto Camino a la servidumbre de 1944, Hayek planteaba que una mayor participación del Estado conduce a la pérdida de libertades y consecuentemente a la aparición y consolidación del totalitarismo. La obra de Hayek es considerada como el punto de partida de un distinto liberalismo, que bajo el nombre de neoliberalismo, postuló una nueva economía de mercado, para sustentar una versión diferente de un capitalismo mucho más radical y con menores regulaciones por parte de un Estado débil.

En la búsqueda de este nuevo orden económico mundial surgieron promotores del neoliberalismo como: Milton Friedman, Walter Lippman, Salvador Madariaga, y por supuesto el propio Hayek, entre otros, quienes fundaron la llamada Sociedad de Mont Pelerín, cuya meta era emprender una cruzada ideológica que combatiera a los enemigos de las libertades económicas, representados principalmente en un comienzo por la Unión Soviética.

Las nuevas ideas no lo eran del todo, dado que abrevaban del pensamiento económico liberal del siglo XIX -de ahí el mote de neoliberales. Su discurso se construyó como una crítica implacable al pensamiento entonces dominante: el keynesiano y las propuestas socialistas del Estado social o planificación central. (Ávila, 2006, p.21)

Bajo sus postulados, si el mercado funciona libremente, sus fuerzas garantizarán el equilibrio económico a través de la fijación natural de los precios, lo cual hace innecesaria e improductiva la intervención del Estado. Sin embargo, ante los años de bonanza del Estado interventor, caracterizado en su papel de benefactor, poco pudieron hacer los promotores de este neoliberalismo.

En los años setenta, cuando de nueva cuenta las grandes crisis mundiales hicieron que aquellos representantes de este nuevo liberalismo, perteneciente al ala más radical de los ideólogos

\footnotetext{
5 “... Se admitió poco a poco el intervencionismo estatal. El Estado Policía, simple guardián del orden, cedió el paso al Estado providencia, regulador de los mecanismos económicos" (Serra, 1988, p. 238).
}

Luis Alberto García Domínguez

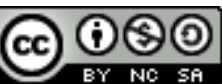

Artículo protegido por licencia Creative Commons 
capitalistas, se encontraron una beta de oportunidades que les permitieron consolidar su postura para ganar terreno en el plano internacional, con lo cual pusieron en duda el buen funcionamiento del Estado benefactor, para criticar severamente la existencia de sindicatos y cualquier otro movimiento obrero, los neoliberales pusieron en la mesa sus propuestas de cambio hacia una mayor desregulación y privatización como la solución para las crisis mundiales ${ }^{6}$.

Este estado de vulnerabilidad mundial permitió que las tendencias neoliberales tuvieran un terreno fértil para encontrar nuevas posibilidades de consolidación de sus ideales ${ }^{7}$.

\section{Conceptualización.}

Para conceptualizar al neoliberalismo es necesario partir del entendimiento del liberalismo. Bajo esta premisa Norberto Bobbio (2006) sostiene, que:

(...) el liberalismo es la doctrina en la que la connotación positiva recae en el término libertad, con la consecuencia de que una sociedad es mejor en cuanto la esfera de la libertad es más amplia y la esfera del poder es más restringida (p.100).

La afirmación de Bobbio es clave para el presente estudio dado que establece las bases de lo que actualmente se vive en las grandes economías mundiales, un Estado cuya característica principal es su debilidad frente al sector privado. Al hablar de una esfera de libertad más amplia para los individuos frente al poder político conlleva también un apartado intrínseco de responsabilidad individual de hacer uso eficiente de esa libertad. La idea de una responsabilidad individual que se transforma colectivamente en una responsabilidad social, al hacer cada individuo uso cabal de su propia responsabilidad se contrapone a la idea de un individualismo utilitarista expuesta por John Stuart Mill. Para John Stuart Mill (2000), la filosofía liberal se sustenta en el llamado individualismo utilitarista, que concibe a los seres humanos como egoístas capaces de colaborar colectivamente siempre que obtengan algún beneficio, en donde cada acción, si es favorable para el placer, se considera como una tendencia buena para los intereses personales, y si es un pesar, entonces se da una tendencia mala.

\footnotetext{
${ }^{6 “ . . . . ~ F r e n t e ~ a ~ l a ~ c r i s i s ~ q u e ~ s e ~ d e s a r r o l l a b a ~ r a ́ p i d a m e n t e, ~ l a ~ i n t e r v e n c i o ́ n ~ e s t a t a l ~ e n ~ l a ~ e c o n o m i ́ a ~ e m p e z o ́ ~ a ~ p e r d e r ~}$ legitimidad lo cual significó la búsqueda de nuevos paradigmas, en algunos casos, para su aplicación en aras de superar las dificultades económicas y, en otros, como respuesta ideológica al estatismo y, en especial, al socialismo cuya influencia crecía, sobre todo, entre las naciones dependientes que se liberaban de las metrópolis que las habían sometido durante muchos años" (Ornelas; 2005, p.31).

7 "Desde los años ochenta, ha tenido lugar un cambio notable, ideológico pero también operacional en alguna medida. El mercado mismo es crecientemente visto como el único medio para promover el desarrollo. Dentro de este marco neoliberal, el crecimiento económico como tal ---sin ninguna redistribución en absoluto-debería permitirnos resolver el dramático problema de la pobreza en todo el mundo sin la mínima contribución impuesta sobre los ricos" ( $\underline{\text { Sachs, 2001, p.154). }}$.
} 
Dentro de esta discusión es menester contraponer la idea de un individuo que actúa por una responsabilidad individual con compromiso social o la del individuo que obra preso de sus instintos egoístas frente al resto de la sociedad. Sea cual fuere la verdad, en el liberalismo, el respeto por la libertad individual y la igualdad de las personas son elementos indispensables. La actuación del Estado estará exclusivamente con la única finalidad de evitar el daño a los demás, limitada a restringir la esfera de la libertad individual.

La última y más poderosa razón para restringir la intervención del Gobierno es el gran mal de aumentar innecesariamente su poder. Toda función que se agregue a las ya ejercidas por el Gobierno es causa de que se extienda su influencia sobre las esperanzas y los temores, y convierte, más y más, a la parte activa y ambiciosa del público en dependiente del Gobierno o de algún partido que trate de llegar a serlo. (Mill, 2000, p. 200)

Con la anterior afirmación, Mill sostiene su postura de preponderancia del individuo sobre el Gobierno, lo que sin duda es cuestionable, pues como el mismo autor afirma, se teme el incremento del poder del Gobierno, sin embargo bajo el neoliberalismo se empieza a temer respecto del incremento del poder del sector privado sobre las esperanzas de la población. En su esencia, el liberalismo implicaba que los derechos individuales son superiores a los derechos sociales, pues bajo esta corriente la razón humana es el árbitro supremo y el Estado se debe poner al servicio de los individuos.

Para Norberto Bobbio (2006), el liberalismo es una concepción del Estado según la cual este tiene poderes y funciones limitados, respecto de sus poderes, el Estado se limita en función de un cuerpo de normas que lo regulan y a su vez norman su relación con los particulares. Por consiguiente, estamos en la posibilidad de hablar del Estado de Derecho, el cual es según Bobbio:

(...) un Estado en el que los poderes públicos son regulados por normas generales (leyes fundamentales o constitucionales) y deben ser ejercidos en el ámbito de las leyes que los regulan, salvo el derecho del ciudadano de recurrir a un juez independientemente para hacer reconocer y rechazar el abuso o exceso de poder. (p. 18)

Así el Estado, en su relación con el individuo y la sociedad, se limita a aplicar la ley para respetar los derechos del ser humano, bajo un control de sus facultades como poder público.

En este sentido, respecto de la función del Estado, en el liberalismo se habla de un Estado mínimo. Sobre este punto John Gray (1994) sostiene que hablar de un Estado mínimo no es lo mismo que hablar de un Estado limitado; porque el primero comprende a aquel que solo se limita a la protección de los derechos negativos, es decir aquel Estado que únicamente

Luis Alberto García Domínguez

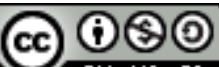

Artículo protegido por licencia Creative Commons 
garantiza la protección contra la fuerza y el fraude, mientras que un Estado limitado puede abarcar muchas más funciones que las del Estado mínimo.

De la discusión anterior se concluye que un Estado liberal presenta como elemento indispensable ser un Estado limitado, aunque no necesariamente al grado de convertirse en un Estado mínimo, ocupado exclusivamente de la defensa de los derechos del ser humano, situación a la que en la actualidad se ha pretendido llevar en algunos países occidentales bajo el neoliberalismo.

Asimismo se resalta la importancia de la comprensión del liberalismo como antecedente directo del neoliberalismo, el cual es en esencia una doctrina en la que el Estado se ve limitado en su esfera de poder, para permitir en consecuencia la ampliación de las libertades individuales. El neoliberalismo es un sistema político que plantea la intervención del Estado en las empresas privadas, para procurarles beneficios, pero con una participación mínima en los aspectos sociales.

El neoliberalismo es la estrategia política con la cual el capital monopólico y las burocracias políticas o élites gubernamentales de las grandes potencias se adaptan al contexto de la globalización y promueven una forma de inserción de las naciones, las comunidades y los individuos en ella y un modo particular de regulación mundial en su seno. (Hernández, 2004, p. 2)

De acuerdo con la anterior afirmación de Pedro Hernández Morales se concibe al neoliberalismo como una estrategia cuya filosofía está sustentada en las bases capitalistas, y en la actualidad ha sido adoptada por los países hegemónicos en materia económica con un afán regulatorio.

Bajo el neoliberalismo se reprivatizan industrias, se promueve la inversión extranjera, se eliminan las subvenciones estatales, con lo que se expande el mercado y los particulares asumen tareas sociales del Estado, tales como la educación y la salud.

Por neoliberalismo hoy se entiende principalmente una doctrina económica consecuente, de la que el liberalismo político solo es una manera de realización no siempre necesario, o sea, una defensa a ultranza de la libertad económica de la que la libertad política solamente es un corolario. (Bobbio; 2006, pp. 97-98)

La anterior afirmación de Bobbio resalta la importancia del aspecto económico en el devenir de los Estados contemporáneos en los que la actividad económica mundial dicta el rumbo de su política, incluso la educativa. Así el neoliberalismo se convierte en una exageración del liberalismo clásico. Entonces los conceptos esgrimidos por Hernández Morales (2004) y Bobbio 
(2006) constituyen la estructura principal de la argumentación teórica bajo la cual se desarrolla la presente investigación.

\section{Educación neoliberal}

\section{Contexto}

Al establecer algunos antecedentes teóricos que caracterizan al modelo neoliberal, es prudente pasar en el presente apartado para analizar uno de los rubros en los que el neoliberalismo se ha manifestado de manera tajante: el ámbito educativo.

Es cierto que los neoliberales muestran un espíritu relativamente tolerante y moderno sobre todo cuando se les compara con los ayatolas de Oriente, pero no cabe duda que constriñen su política educativa a una sociedad particularmente injusta y que sus razonamientos no solo los llevan a pensar en una educación elitista y excluyente, para unos cuantos, sino en una política de estímulos para quienes piensan como ellos, y de desestímulos para quienes se oponen a sus razonamientos. (González; 2001, p.127)

Además de González Casanova, otros autores que señalan la trascendencia de la escuela en la transmisión ideológica, en especial para el actual neoliberalismo, son Baudelot y Establet (2003) quienes afirman que:

(...) la escuela es un aparato ideológico del Estado, es decir un instrumento de lucha de clases: a ese título está profundamente marcado por las condiciones históricas (nacionales) del país donde se efectúa esta lucha así como por las formas concretas que toma. (p. 7)

El sistema educativo establecido por la clase dominante se reafirma en su devenir y se vuelve hegemónico, por consiguiente hablar de educación neoliberal implica también hablar de políticas de educación. De acuerdo con esto, la idea de políticas en el ámbito de la educación superior, nos obliga a pensar necesariamente en planes y programas elaborados por el aparato estatal para la consecución de una serie de objetivos relacionados con la ideología dominante ${ }^{8}$. Las políticas educativas trascienden a esta ideología y la transforman en directrices prácticas que son transmitidas a través de planes de estudio que son incorporados a las escuelas y cuyos contenidos son asimilados por los estudiantes desde los primeros niveles educativos hasta los del ámbito superior.

\footnotetext{
${ }^{8}$ La ideología es, ante todo, masiva y manifiestamente inculcada a los alumnos en forma de un cierto número de temas o de valores en los que se presenta real, sin enmascararse (para los burgueses, la ideología nunca es burguesa; es el "saber", la "verdad", la "cultura", el "gusto", etc,... (Baudelot, 2003, p. 241).
}

Luis Alberto García Domínguez

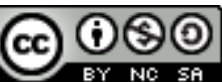

Artículo protegido por licencia Creative Commons 
Para Hernández Morales (2004, pp. 2-3):

(...) con la globalización neoliberal, a la educación ya no se le concibe como un derecho social, hoy es una inversión que debe ser rentable y debe adaptarse a las demandas del mercado, se considera a la educación como una empresa que necesariamente debe demostrar su eficiencia, eficacia, rentabilidad y calidad.

Con base en lo esgrimido por Hernández las instituciones educativas se encuentran inmersas en la turbulencia de la búsqueda de recursos que las hagan eficientes en el aspecto económico, lo cual las aleja cada vez más de su objeto social.

No podemos perder de vista que se ha empezado a consolidar una nueva división internacional del trabajo universitario, donde la producción de conocimientos de punta y la preparación de los cuadros científicos y dirigentes de alto nivel ha quedado generalmente a resguardo de las naciones del centro europeo $y$ americano, para dejar en las orillas del "subdesarrollo" el traslado y consumo de tales saberes y la producción masiva de sus cuadros técnicos y profesionales de nivel medio. (Ibarra, 2002, p. 78)

Los grandes consorcios globalizadores están creando y ahora así lo impulsan, su propio orden educativo, un sistema de enseñanza acorde con sus necesidades, con una visión del mundo y con sus planes de expansión mundial. (Montemayor, 2006, p. 1)

Las corporaciones transnacionales han asumido en la actualidad el papel que el Estado asumía, al establecer tendencias en la educación y en la generación de conocimientos en función de sus intereses específicos. La educación, y en especial la del nivel superior, está redefiniendo cada vez más su objetivo, para incorporar dentro de los órganos directivos de cada institución, esquemas de participación empresarial en la definición de sus políticas educativas y en sus planes de desarrollo, y así provocar que los beneficios de la educación se trasladen a las arcas privadas. Actualmente, la universidad se debate respecto de su objeto, pues este es cada día más alejado de lo social y más cercano a las exigencias del mercado, lo que permite hacer a un lado la posibilidad de recuperar el proyecto originario de la universidad para la sociedad, es decir el proyecto de existencia social, con libertad de pensamiento y consciencia crítica que permite cuestionar al mundo y concebirlo de diferentes maneras.

La educación superior ha proporcionado históricamente la posibilidad de acceder a un estadio superior crítico del entendimiento humano independientemente del área de profesionalización de la que se trate. Las universidades y en general las instituciones de educación superior tienen en su esencia la igualdad de oportunidades, la cual se ve atacada por esta vorágine neoliberal que poco a poco debilita a las instituciones públicas para beneficiar a las privadas.

42

Luis Alberto García Domínguez

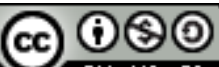

Artículo protegido por licencia Creative Commons 
El objeto social de la universidad, definido como un contrapeso fundamental del poder, deja de serlo y se convierte poco a poco en la asimilación de la naturaleza mercantil en la educación. Así, las instituciones de educación superior pierden su objeto social consistente en la salvaguarda de la cultura, el libre pensamiento y el pensamiento crítico en pro de la comercialización del conocimiento en el ámbito global, para redefinir de facto su devenir académico y administrativo.

Piña afirma que:

El proyecto neoliberal vislumbra la transnacionalización del mercado universitario, pues ve en él un mercado con enormes posibilidades de generación de capitales, que desde su perspectiva, se encuentra ahora fragmentado, sin gestión profesional y con pocos insumos tecnológicos. (Piña, 2006, p. 116)

Lo anterior supone llegar a una concepción de la educación superior como una mercancía más, para cuya oferta es menester la privatización, pero sobre todo la mercantilización en el ámbito global. La incorporación de órganos externos en las instituciones educativas, provenientes principalmente del sector privado, ha posibilitado la intromisión de este sector en el objeto social de estas organizaciones.

Un argumento que se reitera en el pensamiento neoliberal, es la participación ciudadana, ¿pero qué nivel de participación se podría tener cuando el grueso de sus ciudadanos, no son partícipes de un espacio formativo universitario, no solo con fines formativos en sentido profesional, sino paralelamente con fines de formación ciudadana y bajo un ideal de ciudadano participativo, analítico y comprometido con su tiempo? (Piña, 2006, p. 121)

Otra afirmación interesante, aportada por Piña $(\underline{2006})$ es la referente al énfasis que se pone actualmente en la nueva concepción de los alumnos como clientes, al decir que: "ver como clientes potenciales del sistema educativo a los alumnos, lleva a suponer que habrá que adecuar la provisión de los servicios educativos a sus posibilidades de pago" (p. 121). Situación por demás riesgosa y que pone en juego nuevamente la visión neoliberal, que persigue convertir a las universidades en empresas al servicio de su propia ideología.

Así, afirma Ornelas (2006):

(...) la política restrictiva del financiamiento fiscal, ha provocado múltiples dificultades al desarrollo de las universidades públicas hoy colocadas en una situación que les exige formar a los jóvenes en la frontera de la ciencia y la tecnología sin disponer de recursos materiales y financieros para hacerlo. (p. 11) 
En general, las afirmaciones anteriores son aplicables al ámbito nacional, es entendible que la realidad educativa para México y Latinoamérica se encuentra inmersa en los lineamientos establecidos en el escenario global, mismos que pretenden la creación de profesionales idóneos a las necesidades del mercado. Entonces, es con base en lo anteriormente sostenido que estamos en posibilidades de hablar de una educación inmersa en el mercado ${ }^{9}$.

La educación es vista como un negocio más dentro del propio modelo, lo que la convierte en, además de un instrumento de transmisión ideológica, un área de oportunidad para grandes consorcios educativos a nivel mundial, cuya penetración en México cada día es más visible.

\section{Políticas educativas}

Tras esbozar el marco económico en el que se desarrolla actualmente el quehacer educativo, es necesario pasar al espacio de aplicabilidad en el que se plasma esta vertiente a través de directrices enraizadas en el modelo neoliberal y que llegan a la esfera educativa por medio de políticas.

La evaluación educativa y la búsqueda de la calidad son dos constructos concatenados en su temporalidad y aplicación, que a manera de políticas, en los últimos años, han surgido en la palestra académica con claros antecedentes teóricos establecidos en el seno de una economía neoliberal.

\section{La evaluación educativa}

Otro de los tópicos obligados dentro del entorno educativo es el referente a la evaluación, dado que esta se ha convertido en el instrumento a través del cual el sistema imperante verifica el cumplimiento de la lógica neoliberal aplicada en forma ideológica a la educación ${ }^{10}$.

De acuerdo con Ramírez (2000) el surgimiento formal de la evaluación se encuentra ligado al desarrollo capitalista. Según esta misma autora:

La evaluación se convierte en una estrategia de la racionalización social que posibilita la competitividad y la calidad, que de acuerdo al discurso oficial le permite al país su introducción a los mercados mundiales, a los procesos de globalización del capital, pero lo que no indica ese discurso es que esa participación siempre será en

\footnotetext{
9 "La estructura de producción y realización mundial del capital determina la estructura ocupacional mundial, la que a su vez condiciona la estructura del sistema educativo mundial, del cual los sistemas educativos nacionales son funciones o subsistemas dependientes (Chomsky, 2002, p. 110)".

10 "La evaluación opera como tecnología de diferenciación a partir de la muy precisa contabilidad de los productos, sin preocuparse demasiado por los procesos (Ibarra en Ossa, 2002, p.198)".
}

44

Luis Alberto García Domínguez

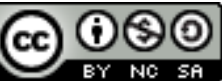

Artículo protegido por licencia Creative Commons 
desventaja por más evaluaciones y certificaciones internacionales que se realicen, pues la incorporación al mercado mundial continúa atada al desarrollo de las fuerzas productivas, a la división internacional del trabajo y a la organización económica de los centros hegemónicos del gran capital. (p. 5 )

Con respecto a las anteriores afirmaciones se resalta el sentido que se le da a la evaluación, para definirla como una estrategia de racionalización, situación que puede verse patente en el contexto de las universidades mexicanas a través de la asignación de recursos con base en los resultados de diversos tipos de evaluaciones creadas bajo el mismo contexto neoliberal. Sin embargo, para concordar con la tesis de Rosa María Ramírez, es necesario profundizar desde diversas vertientes en este proceso que actualmente viven las instituciones educativas del país, por lo cual se recoge la concepción que la Asociación Nacional de Universidades e Instituciones de Educación Superior (ANUIES) tiene de este proceso al expresarse que:

(...) la evaluación ha sido definida como un proceso continuo, integral y participativo, que permite identificar una determinada circunstancia educativa, analizarla y explicarla mediante información relevante, lo que permite generar juicios de valor que sustenten la toma de decisiones. (Juárez, et al. 2006, p. 2)

Con la anterior aseveración se pueden contrastar dos perspectivas desde las cuales puede ser entendida la evaluación, en la primera se le ve desde el punto de vista de su finalidad, mientras que en la segunda se atiende al aspecto puramente práctico del proceso. Esta comparación permite apreciar lo complejo del tema de la evaluación, pues, aun cuando se le puede definir con mediana facilidad, es necesario identificar el contexto bajo el cual se le esgrime, y más aún la intencionalidad con la que se le establece. El término evaluación en consecuencia es aplicado de muy diversas formas las cuales dependen del contexto en el que se le utilice, por lo que es posible encontrar un gran número de definiciones al respecto.

En este sentido, bien es cierto que la evaluación aplicada a la educación surge de la necesidad de medir el grado en que los conocimientos son adquiridos por los estudiantes. Sin embargo quedarnos con esta concepción nos aleja del sentido de la evaluación en la que se ha inscrito a las instituciones educativas actualmente, dado que este concepto ha evolucionado y se le ha utilizado para abarcar a toda la vida institucional de una organización educativa.

Así en el mismo tenor, al seguir otros enfoques del mismo concepto, Pacheco (2001) establece que:

(...) las Instituciones de Educación Superior, pese a los procesos de evaluación sugeridos por la SEP, ANUIES y FIMPES, están lejos de cumplir con las expectativas de organización académica, currículum y eficiencia administrativa, ya que están basadas en preceptos y metodologías ajenas a estas tendencias. (Pacheco, 2001, p. 2) 
Este mismo autor va más allá, al señalar que los modelos de evaluación, acreditación y certificación están sometidos a recomendaciones de agencias internacionales con base en una idea de modernización global del aparato educativo.

Ahora bien, esta contextualización de la evaluación en educación refleja la visión de una política educativa que la concibe como un instrumento para la toma de decisiones, más que una interpretación de aquella en la que se le vea como una manera de establecer estrategias e inclusive políticas que permitan mejorar a las instituciones.

Cualquier estudio de evaluación institucional y las sugerencias y decisiones que se deriven, se plantea siempre frente a un referente que se utiliza como contraste o como meta. Este referente es el tradicional término de calidad institucional, de los programas, de los profesores (...) y en general, de todos los elementos de la organización. El equipo evaluador deberá establecer claramente este referente previamente a desarrollar su trabajo. (Álvarez, 2002, p. 117)

La afirmación de Álvarez permite resaltar precisamente el referente establecido como modelo por alcanzar para las instituciones, el cual se define en términos de calidad o calidad educativa que alude precisamente al ámbito de estas organizaciones.

Para Yzaguirre (2005):

La evaluación es un importante factor de calidad y para que un sistema educativo que ha planeado como meta la calidad en la educación que ofrece, es necesario se establezcan mecanismos de evaluación en su conjunto, para analizar los aprendizajes de los estudiantes, los procesos educativos, el currículo, los profesores y las escuelas. $(\mathrm{p} .422)^{11}$

Al comparar las tesis de los anteriores autores con los primeros de este apartado se esboza que la relación evaluación-calidad educativa, es el eslabón bajo el cual en el contexto de la política educativa neoliberal se han conformado una serie de estrategias de racionalización de los recursos que se aportan a estas instituciones para su operación y desarrollo.

El Estado, ante la revalorización jurídica y política, en los últimos años fue cambiando su relación hacia las Instituciones de Educación Superior y sus enfoques académicos son determinados por criterios cualitativos y procesos de evaluación

\footnotetext{
11 "En este contexto es un hecho que la evaluación es un factor necesario para contextualizar la calidad educativa, sin embargo para que efectivamente pueda existir una relación entre evaluación y calidad de la educación, se requieren importantes mediaciones cuya ausencia ha impedido, en muchos lugares y en el pasado, que la existencia de evaluación asegure calidad de la educación" (Yzaguirre, 2005, p. 422).
}

46

Luis Alberto García Domínguez

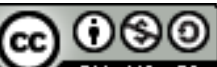

Artículo protegido por licencia Creative Commons 
ajenos a la realidad didáctica nacional y buscan privilegiar, por ejemplo, a otros sectores sociales que podrían pagar colegiaturas más caras. (Pacheco, 2001, p. 1)

Esta situación anterior cada vez es más visible en las facilidades otorgadas a las instituciones educativas privadas para la ampliación de su oferta educativa y las limitaciones bajo las cuales se somete a la educación pública en el sentido de responder con programas educativos a las exigencias del propio modelo neoliberal.

\section{La calidad educativa}

La literatura sobre calidad es basta y casi toda se encuentra inmersa en las disciplinas administrativas o de naturaleza industrial. Históricamente han destacado autores como Juran e Ishikawa, por citar algunos. La historia de los modelos de calidad data de los años subsecuentes a la Segunda Guerra Mundial, después de la cual surgieron principalmente dos corrientes, una representada por la llamada revolución japonesa de la calidad, la cual consistió básicamente en el mejoramiento de la calidad de los productos japoneses y la segunda, en la que se buscó resaltar la calidad del producto japonés en un mundo que hasta esa época consideraba sus productos como de mala calidad, lo que implicó significativamente, un cambio en las relaciones laborales. El término calidad surgió así en el ámbito empresarial y cobró fuerza a raíz de los trabajos de los teóricos norteamericanos E.W. Deming y J. Juran, quienes contribuyeron principalmente durante los años cincuenta a integrar un verdadero concepto de calidad, el que en los últimos años fue evolucionando hasta abarcar no solamente al producto, sino también al servicio relacionado con la satisfacción del cliente. Ahora se dice que algo tiene calidad si cumple las normas de su diseño o fabricación y si satisface aquello para lo que fue creado ${ }^{12}$.

De acuerdo con lo anterior, es precisamente bajo esta lógica del concepto que se justifica su inmersión en actividades ajenas a la industria, lo que ha permitido la inclusión del concepto en ámbitos tan distantes como el educativo. Lo interesante aquí es establecer si a pesar de esta amplitud que ha tomado el concepto de calidad puede ser medianamente entendido desprovisto del propósito o de la política bajo la cual se esgrime. La respuesta es encontrada en la misma evolución del concepto. La lógica del mercado lo adapta a sus necesidades y convierte a la calidad en una herramienta de mercadeo, en cuya óptica se promovían los productos de la industria y actualmente hasta a los seres humanos respecto de su formación.

Otro aspecto interesante es que el mismo término calidad, además de ser utilizado como insumo mercadológico, se le utiliza como instrumento de estandarización y por tanto de

\footnotetext{
12 Para Navarro, 1998 y Readings, 1997, "La característica esencial de la transformación de la universidad experimentada a lo largo de las últimas dos décadas, se encuentra en la modificación radical de su régimen de gobierno. Es posible apreciar, por ejemplo, la incorporación de nuevas estrategias discursivas basadas en la retórica de la excelencia. (Ibarra, 2002, p. 81)
}

Luis Alberto García Domínguez

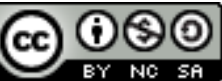

Artículo protegido por licencia Creative Commons 
dominación ideológica, pues lo que se promueve más que una cultura de calidad, es la búsqueda de la penetración de formas de vida evidentemente distintas de las que los utilizan, con lo cual se pone en riesgo a largo plazo la identidad y las costumbres de los pueblos a quienes se les impone.

Para Cantú (2001):

(...) en general, se puede decir que calidad abarca todas las cualidades con las que cuenta un producto o un servicio para ser de utilidad a quien se sirve de él. Esto es, un producto o servicio es de calidad cuando sus características, tangibles e intangibles, satisfacen las necesidades de sus usuarios. (p. 5 )

Para la discusión se han esgrimido muchas otras definiciones de calidad, las cuales según la época y la intencionalidad con la que fueron establecidas, se enfocan en aspectos como las cualidades o características vertidas normalmente en un producto o servicio. Gryna (1995) sintetiza el concepto de calidad al señalar que "una definición breve que tiene mucha aceptación es: la calidad es la satisfacción del cliente" (p. 3).

Más allá de lo esgrimido por los autores anteriores es palpable la ambigüedad del concepto, el cual según las necesidades del entorno ha ido sufriendo modificaciones que lo ajustan a lo lógica neoliberal en la que fue creado. El concepto calidad surge con la perspectiva de mejorar los procesos industriales para hacer un uso más eficiente de los recursos materiales y humanos, así como abaratar los costos, reducir el personal en las empresas y en general favorecer aún más las condiciones de los dueños del capital en menoscabo de la clase trabajadora.

Poco a poco esta búsqueda de la calidad se fue garantizando a través de la estandarización internacional con base en reconocimientos que pudieran ser respetados en todos los ámbitos internacionales. Ahora bien, si el concepto de calidad es ambiguo y dependiente del contexto en el que se le argumenta, el de calidad educativa es aún más ambiguo por lo que requiere un análisis profundo de la intencionalidad con la que se le utiliza ${ }^{13}$.

\footnotetext{
13 “ ... De acuerdo a Álvarez Tostado (1997), maestro chileno, la calidad de la educación parece surgir de manera espontánea, ya que no existen registros confiables que precisen una fuente o un momento. Sin embargo señala este mismo autor, la política educativa de la administración Reagan y, casi simultáneamente, la Organización para la Cooperación y Desarrollo Económicos (OCDE) se preocuparon por el problema de la calidad de la educación" (lbarra, 2000, p. 2).
} 
Para Ornelas (2000), al analizar un documento elaborado por Grupo Financiero Bancomer, con base en las propuestas educativas del Banco Mundial ${ }^{14}$, "el criterio de calidad sería el de la demanda, pues se parte de que en el mercado solo sobreviven los negocios que satisfacen plenamente las necesidades de los consumidores (p. 4)".

Al observar la afirmación de Ornelas, se establece claramente la importancia del contexto pues deja ver la intencionalidad con la que es esgrimido el concepto de calidad educativa; Ornelas (2000) hace notar la visión de la educación relacionada con las demandas del mercado de acuerdo con las exigencias de las agencias internacionales respecto de lo que debe ser la educación bajo el esquema neoliberal.

Según Freire (2001) "no hay por último, educación neutra ni calidad por las que luchar -en el sentido de reorientar la educación - que no implique también una opción política y no exija una decisión, también política, de materializarla" (pp. 48-49).

La afirmación de Freire fija el devenir de la educación bajo la directriz establecida en el marco de una política definida más allá del ámbito educativo, lo que la desprovee de su esencia y la condiciona a intereses distintos de los esencialmente educativos.

Para la UNESCO (1997):

(...) en general se suele abordar el concepto de calidad a través de dos aproximaciones diferentes: una de ellas procura discutirlo y definirlo en forma constitutiva o conceptual y la segunda se centra en la operacionalización de la calidad y se refiere más propiamente al nivel de logros en educación. (LLECE, OREALC/UNESCO, 1997, p. 5)

La segunda de las maneras de abordar el tema de la calidad, de acuerdo con lo establecido por la UNESCO, parece ser la que cobra mayor vigencia en la actualidad, pues las instituciones educativas de nivel superior difunden reiteradamente sus logros educativos como galardones de calidad educativa, para dirigir su vida institucional con base en indicadores de calidad.

Rodríguez (1991) sostiene en relación con la calidad educativa que "la calidad es un concepto multidimensional, relativo a los objetivos y actores del sistema y esto es muy complejo en el caso de la universidad, un sistema multifuncional y con muchísimos actores diversos" (Álvarez, 2002, p. 117).

\footnotetext{
14 “Afirma Friedman (1980, pp. 235-236) solo sobrevivirán las escuelas que satisfagan a sus clientes; del mismo modo que sólo continúan los restaurantes y bares que agradan a sus clientes. La competencia se ocuparía de ello" (Ornelas, 2000, p. 4).
} 
Con base en lo planteado por Rodríguez el, de por sí ya divergente, concepto de calidad se hace aún más complejo al introducírsele en el ámbito educativo, en especial en el de las universidades.

En el mismo tenor, respecto de la calidad, para Silva (2002) "el concepto no es definido en sí mismo, sino en relación con tres referentes: 1) Desarrollo humano del alumno; 2) Requerimientos de la sociedad; y 3) Entorno internacional" (p. 118). De acuerdo con lo anterior, el mismo autor sostiene que en el primer caso se habla de una continuidad en el crecimiento del ser humano en relación con su libertad responsable y sus capacidades. Respecto del segundo, este se da en la relación del individuo con su país, a través de valores como la responsabilidad, el respeto, el compromiso y la solidaridad, además de una conformación de sus actitudes con relación a los retos productivos; para dejar en tercer lugar, esta misma relación, pero concebida en el plano global.

Así como Acosta Silva hace relación a tres referentes es notoria la gran cantidad de conceptos diferentes relacionados con el tópico de la calidad educativa, Dendaluce (1991), "por ejemplo, al referirse a la calidad educativa, resalta tres dimensiones en su definición: a) respuesta a las necesidades educativas; b) coherencia de los distintos componentes y partes del proceso; y c) satisfacción de los implicados" (Álvarez, 2002, p. 118). Dimensiones cuyo valor están en función de la utilidad con la que fueron planteadas.

Tal y como lo afirma Escudero (1993), “(...) la calidad, puede significar muchas más cosas y no es un concepto fácil de definir. Por eso se habla sobre la cuestión de la calidad, como expresión de este problema" (Álvarez, 2002, p. 117). Pues es claro que no hay una sola calidad universalmente aceptada, una calidad perfectamente definida, sino más bien calidades atribuidas por las personas.

Con base en lo escrito, el concepto mismo de calidad educativa refiere a una apreciación valorativa de las actividades desarrolladas en educación, es decir, se requiere la emisión de juicios de valor respecto de los elementos intervinientes en el proceso académicoadministrativo.

Las grandes potencias establecen directrices económicas internacionales que someten a la educación para establecer políticas en función del aseguramiento de la eficiencia institucional en relación con una serie de indicadores internacionales.

Para Freire (2001):

(...) Calidad de la educación; educación para la calidad; educación y calidad de vida, no importa en qué enunciado se encuentren, educación y calidad son siempre una 
cuestión política, fuera de cuya reflexión y comprensión no nos es posible entender ni una ni otra. (p. 48)

Sin embargo, en un análisis más profundo, la calidad educativa representa un concepto creado para una finalidad específica en un momento determinado. Resulta imposible entender su significado si no se le analiza en el contexto en el cual surgió, pero sobre todo si no se consideran los elementos y las finalidades que en su constitución conforman su intención oculta.

\section{Conclusiones}

Con base en lo discutido en el presente trabajo se establecen las siguientes consideraciones:

1. El neoliberalismo como estrategia política y económica sustentada en el debilitamiento del Estado y la supremacía de los intereses económicos particulares ha llevado en los últimos años a la mercantilización de la vida social, como producto de una ideología que busca su perpetuidad y promueve el acaparamiento de los recursos limitados a costa de los demás.

2. En la búsqueda de su perpetuidad el neoliberalismo hace uso de la educación como instrumento histórico de transmisión ideológica con el fin de consolidar en sus distintos niveles los requerimientos que en materia económica se establecen para el sostenimiento de los grandes capitales.

3. Como estrategia política neoliberal se han gestado una serie de mecanismos con el fin de condicionar el sostenimiento de estas organizaciones para su incorporación a esquemas de evaluación de sus distintas actividades académicas y administrativas.

4. Del mismo modo bajo el contexto neoliberal en el ámbito educativo se han creado conceptos igualmente enraizados en ambientes empresariales como es el de calidad, al cual se le agrega el concepto "educativo" para crear un hibrido cuya definición se adecua al contexto en el cual se le esgrime.

5. Así, la calidad educativa se ha convertido en uno de los pilares de la educación del siglo XXI para los países que tienen en el neoliberalismo su estrategia política y económica dominante.

Por consiguiente, la búsqueda de la llamada calidad educativa constituye un mecanismo creado en el seno de una política educativa cuya finalidad en esencia está determinada por las exigencias de las agencias internacionales con la principal intención de establecer ideológicamente la perpetuación del esquema neoliberal, la creación en los países pobres de una masa obrera calificada que no aspire a los puestos directivos, además de la racionalización de los recursos a las instituciones educativas de estas naciones con miras a un adelgazamiento de las obligaciones del propio Estado, específicamente en el ámbito de la educación superior, tal y como el propio modelo neoliberal lo promueve.

Luis Alberto García Domínguez

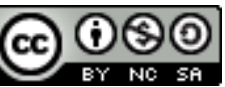

Artículo protegido por licencia Creative Commons 
Asimismo, la reaparición del término calidad educativa ha representado un ícono que ha marcado una de las directrices educativas en México. A pesar de que no hay un acuerdo claro respecto de lo que debe entenderse por la calidad educativa, parece emerger la visión de ubicar a este concepto mucho más en relación con los objetivos neoliberales de la política mexicana. $Y$ si como parece ser, la lógica educativa se ha orientado, especialmente en el nivel superior, a satisfacer las necesidades del sector privado, en especial a intereses que buscan profesionistas cada día más actuantes y menos pensantes, es entonces que se podrían plantear dos premisas. Bajo la primera premisa, el modelo neoliberal crea una ficción con el término calidad educativa, y a su vez plantea la forma de garantizarla a través de diferentes mecanismos, tales como la certificación ISO, la cual cumple con la ficción de garantizar una calidad educativa en un círculo perfecto de simulación. Por otro lado, bajo una segunda premisa, al suponer por un instante que la calidad educativa pueda ser concebida como una manera de mejorar el servicio educativo que es proporcionado, también habría que cuestionar si es la manera adecuada, al tomar en cuenta que en su origen no fue pensada para su implementación en instituciones educativas y en su práctica no se han encontrado evidencias significativas y fidedignas de su aportación a la educación.

De cualquier forma, es necesario resaltar que el papel del Estado como principal patrocinador del sistema educativo no debe ser cedido a los intereses del mercado. Ante el impacto de la globalización, la tendencia especialmente en el ámbito de la educación superior lleva a prever para este nivel un futuro mucho más elitista, en el cual las grandes universidades, ya no serán públicas, sino privadas y a las que solo tendrán acceso unos cuantos, cuya aceptación no será con base en capacidades, sino en el poder adquisitivo que se tenga para su ingreso.

El riesgo de no cuestionar en la actualidad estas prácticas neoliberales será a la larga una mayor hegemonía cultural de los países que las imponen y un sistema educativo como instrumento de dominación. Por lo anterior, se propone devolver su esencia a la educación superior, en la que se privilegie la libertad de cátedra, el libre pensamiento y el fomento al análisis crítico de la realidad local y nacional, y hacer a un lado los mecanismos racionalizadores de los recursos económicos con base en directrices neoliberales cuyo eje se encuentra lejos del quehacer educativo.

\section{Referencias}

Acosta, A. (enero-abril, 2002). En la cuerda floja. Riesgo e incertidumbre en las políticas de educación superior en el foxismo. Revista Mexicana de Investigación Educativa, 7(14), 107-132. Recuperado

de http://www.comie.org.mx/v1/revista/portal.php?idm=es\&sec=SC03\&\&sub=SBB\&criteri o=ART00332 
Álvarez, I. (2002). Planificación y desarrollo de proyectos sociales y educativos. México: Limusa Grupo Noriega Editores. Recuperado de http://www.noriega.com.mx/shop/item.asp?itemid $=8138$

Ávila, J. (2006). La era neoliberal. México: OCEANO. Recuperado de: http://oceano.mx/fichalibro.aspx?id=5374

Baudelot, C. y Establet, R. (2003). La escuela capitalista en Francia. México: Siglo XXI editores s.a. de c.v. Recuperado de http://www.sigloxxieditores.com/libros/La-escuelacapitalista-en-Francia/9788432302084

Bobbio, N. (2006). Liberalismo y democracia. México: Fondo de Cultura Económica. Recuperado de https://www.fce.com.ar/ar/libros/detalles.aspx?IDL=1262

Cantú, H. (2001). Desarrollo de una cultura de calidad. México: Editorial McGraw Hill.

Chomsky, N. y Dieterich, H. (2002). La sociedad global. México: Editorial Joaquín Mortiz, S.A. de C.V. Editorial Planeta Mexicana, S.A. de C.V.

Freire, P. (2001). Política y educación ( $5^{\text {ta }}$ ed.). México: Siglo veintiuno editores S.A. de C.V. Recuperado de: https://goo.gl/bJEA2g

González, P. (2001). La universidad necesaria en el siglo XXI. México: Ediciones ERA. Recuperado de http://www.edicionesera.com.mx/la-universidad-necesaria-en-el-siglo-xxi-info

Gray, J. (1994). Liberalismo. España: Alianza Editorial S.A. Recuperado de http://www.mcgrawhill.com.mx/cgi-bin/book.pl?isbn=970106142X\&division=mexh

Hernández, P. (2004). Impacto de la globalización en las Políticas Educativas: Hacia la construcción de alternativas. Recuperado de http://firgoa.usc.es/drupal/node/4922

Ibarra, E. (enero-abril, 2002). La nueva universidad en México: transformaciones recientes y perspectivas. Revista Mexicana de Investigación Educativa, 7(14), 75-105. Recuperado de

http://www.comie.org.mx/v1/revista/portal.php?idm=es\&sec=SC03\&\&sub=SBB\&criteri $\underline{\mathrm{o}=\mathrm{ART} T 00331}$

Ibarra, L. R. (2000). Calidad de la educación y académicos. Trabajo presentado en el Primer Congreso Retos y Expectativas de la Universidad, México. Recuperado de http://www.congresoretosyexpectativas.udg.mx/Congreso\%201/Mesa\%20G/mesag 3.pdf 
Ishikawa, K. (1997). ¿Qué es el control total de calidad? Colombia: Grupo Editorial Norma. Recuperado de http://books.google.es/books/about/Qu\%C3\%A9_es_el_control_total_de_calidad.html? id=MWGOXKteTQwC

Gryna, F. M. (1995). Análisis y planeación de la calidad. México: McGraw Hill.

Juárez, S. y Paredes, V. (2006). Los procesos de calidad en la Universidad Autónoma de Tlaxcala. Ponencia presentada en el 60 Congreso Internacional "Retos y expectativas de la Universidad", México. Recuperado de http://www.congresoretosyexpectativas.udg.mx/Congreso\%206/Eje\%204/Ponencia 26. pdf

LLECE, OREALC/UNESCO. (1997). Laboratorio latinoamericano de evaluación de la calidad de la educación. 1 Marco conceptual. Recuperado de http://unesdoc.unesco.org/images/0018/001836/183650s.pdf

Mill, J. S. (2000). Sobre la libertad. España: Alianza Editorial S.A. Recuperado de http://www.alianzaeditorial.es/libro.php?id=2947276\&id col=100521

Montemayor, C. (2006). Universidad pública y privatización del conocimiento. México: La Jornada. Recuperado de http://firgoa.usc.es/drupal/node/33482

Ornelas, J. (2000). Los riesgos de las Instituciones públicas de educación superior. Ponencia presentada en el 10 Congreso Internacional "Retos y expectativas de la Universidad", México. Recuperado de http://www.congresoretosyexpectativas.udg.mx/Congreso\%201/Mesa\%20D/mesad_6.pdf

Ornelas, J. (2005). El siglo XX mexicano, economia y sociedad III. Benemérita Universidad Autónoma de Puebla. México: Dirección General de Fomento Editorial.

Ornelas, J. (2006). Reflexiones en torno a los retos de la universidad pública mexicana en los tiempos de crisis Del paradigma neoliberal. Ponencia presentada en el 60 Congreso Internacional "Retos y expectativas de la Universidad", México. Recuperado de http://www.congresoretosyexpectativas.udg.mx/Congreso\%206/Eje\%201/Ponencia 54. pdf 
Ossa, J. (enero-abril, 2002). Sin textos, Textos y Contextos de Universidad (Reseña). Revista Mexicana de Investigación Educativa, 7(14). 191-201. Recuperado de http://www.comie.org.mx/v1/revista/visualizador.php?articulo=ART00336\&criterio=htt p://www.comie.org.mx/documentos/rmie/v07/n014/pdf/rmiev07n14scE00n02es.pdf

Pacheco, E. y Ferrer, M. (2001). Neoliberalismo y Educación: Los Procesos de Evaluación, Acreditación y Certificación en las Instituciones de Educación Superior. Ponencia presentada en el 2 o Congreso Internacional "Retos y expectativas de la Universidad", México. Recuperado de: http://www.congresoretosyexpectativas.udg.mx/Congreso\%202/Mesa\%202/c)\%20Eval uaci\%F3n,\%20acreditaci\%F3n\%20y\%20certificaci\%F3n/2.c.3..pdf

Pacheco, R. y González, A. J. (2000). La Universidad del futuro ¿Pública o Privada?: Los procesos de evaluación, acreditación y certificación de las IES. Ponencia presentada en el 10 Congreso Internacional "Retos y expectativas de la Universidad", México. Recuperado de: http://www.congresoretosyexpectativas.udg.mx/Congreso\%201/Mesa\%20E/mesae 8.pdf

Piña, I. (abril-junio, 2006). La universidad del siglo XXI. Revista de educación superior, 35(138). 115-122. Recuperado de http://publicaciones.anuies.mx/revista/138/4/1/es/launiversidad-en-el-siglo-xxi

Sachs, W. (2001). Diccionario del desarrollo, una guía del conocimiento como poder. México: Servicios de Edición e Información Galileo, S.A. de C.V. Universidad Autónoma de Sinaloa

Serra, A. (1988). Ciencia política. Editorial Porrúa. S.A. México. Recuperado de https://www.porrua.mx/pagina-interior.php?id=373659

Yzaguirre, L. (2005). Calidad educativa e ISO 9001-2000 en México. Revista Electrónica Iberoamericana sobre Calidad, Eficacia y Cambio en Educación, 3(1), 421-431. Recuperado de http://www.ice.deusto.es/RINACE/reice/Vol3n1 e/Yzaguirre.pdf 